\title{
Çok ileri Maternal Yaş Gebelik Sonuçlarının Değerlendirilmesi
}

\author{
Rukiye Akarsu $\bullet$, Leyla Şahiner@
}

Bozok Üniversitesi, Ebelik, Yozgat, Türkiye

Rukiye Akarsu, Dr. Öğr. Üyesi Leyla Şahiner, Ebe
Illetişim:

Dr. Öğr. Üyesi Rukiye Akarsu Bozok Üniversitesi, Ebelik, Yozgat, Türkiye Tel: +903542421034

E-Posta: rukiye-hobek@hotmail.com
Gönderilme Tarihi : 01 Kasım 2018 Revizyon Tarihi : 16 Nisan 2019 Kabul Tarihi : 23 Haziran 2019

\section{ÖZET}

Amaç: Çok ileri anne yaşında olan gebelerde belirgin bir şekilde artmış sezaryen doğum oranları, maternal ve fetal risk bulunmaktadır. Bu nedenle bu çalışmada 40 yaş ve üzeri gebelerin gebelik sonuçlarının incelenmesi amacıyla yapıldı.

Yöntem: 40 yaş ve üzeri doğum yapan 130 gebe çalışmaya dâhil edildi. Bu gebelerin obstetrik özellikleri, doğum şekilleri, sezaryen endikasyonları değerlendirildi.

Bulgular: Gebelerin yaş ortalaması $41,63 \pm 2,02$, paritesi $3,39 \pm 1,3$ gravidası $3,93 \pm 1,8$ olarak bulundu. Doğum şekilleri incelendiğinde \%37'sinin normal doğum, \%63'ünün sezaryen doğum yaptığı saptandı. Sezaryen endikasyonlarının sırasıyla, \%35 önceki sezaryen doğum, \%21fetal distres, \%13 malprezentasyon, \%11 ilerlemeyen eylem olduğu belirlendi.

Sonuçlar: Çok ileri maternal yaşta sezaryen doğum oranları önemli ölçüde artmaktadır. Obstetrik ve perinatal risklerin erken teşhisi için çok ileri maternal yaşta antenatal takiplerin çok dikkatli yapılması gerekmektedir.

Anahtar sözcükler: Çok ileri maternal yaş; sezaryen oranı; sezaryen endikasyonları

\section{EVALUATION OF VERY ADVANCED MATERNAL AGE PREGNANCY RESULTS}

\section{ABSTRACT}

Objective: Significantly increased cesarean birth rates, maternal and fetal risks are present in very advanced maternal age. Therefore, we aimed to examine obstetric outcomes of pregnant women over 40 years-old.

Method: A total of 150 pregnant women giving birth over 40 years of age were recruited in the study. A study evaluating the obstetric features, forms of birth, cesarean section indications is organized.

Results: The mean age of the pregnant women was $41.63 \pm 2.02$, mean parity was $3.39 \pm 1.3$, mean gravida was $3.93 \pm 1.8$, when the mode of delivery was investigated, rate of normal spontaneous vagina delivery was $\% 37$ while the rate of cesarean section was $\% 63$. When cesarean section indications were investigated respectively, previous cesarean section $\% 35$, Fetal distress $\% 21$, malpresentation $13 \%$, progressive action $11 \%$ (miscarriage).

Conclusion: There is a significant increase in cesarean rates in advanced maternal age. For early detection of obstetric and perinatal risks, antenatal care of the very advanced maternal age pregnancies should be done carefully.

Keywords: Very advanced maternal age; cesarean rates; cesarean indications

luslararası Obstetrik ve Jinekoloji Federasyonu [International Federation of Gynecology and Obstetrics (FIGO)] tarafından, uygulamaların standardize edilmesi ve tedavi protokolleri oluşturulabilmesi açısından, 35 yaş ve üzeri gebelikler için "ileri anne yaşı"; 40 yaş ve üzeri gebelikler için ise "çok ileri anne yaşı" ifadesi kullanılmaktadır (1). 
Dünyada son on yılda, evlilik yaşının artması, ikinci evlilikler, ileri eğitim ve kariyer gelişimi için daha geniş fırsatların olması, aile planlaması yöntemlerinin kullanım oranların artması, daha iyi kontraseptif seçeneklerin olması doğurganlığın ileri yaşlara kayma eğilimini yaygınlaştırmıştır. Ayrıca daha fazla kadın yardımcı üreme tekniklerinin avantajlarını kullanarak gebeliği hayatlarının beşinci on yıla ertelemektedir $(2,3)$. Türkiye'de de çok ileri anne yaşı gebelikleri yıllar içinde artış göstermektedir. 2015 yılında doğumların \%2,85'ini çok ileri maternal yaş gebelikler oluşturmuştur (4).

Çok ileri anne yaşında olan gebelerde belirgin bir şekilde artmış sezaryen doğum oranları, maternal ve fetal risk bulunmaktadır (5).

4 yıllık sezaryen doğum oranlarının incelendiği bir çalışmada 35 yaş üstü gebelerde sezaryen doğum oranın $\% 33,2$ olduğu belirtilmektedir (6).

Yapılan çalışmalar hipertansiyon, gestasyonel diabetes mellitus (DM), postpartum kanama, prematüre doğum, plasenta previa, plasenta dekolmanı, sezaryen, düşük doğum ağırlığı, intrauterin gelişme geriliği (IUGG), makrozomi gibi bulguların ileri maternal yaşta arttığını belirtmektedir (5, 7-11). Bu nedenlerden dolayı artmış maternal yaşta sezaryen doğum endikasyonları da değişebilmektedir. Literatürdeki çoğu çalışma 35 yaş altı gebeliklerin gebelik ve doğum özelliklerini değerlendirmiştir. Ancak çok ileri maternal yaşa sahip yüksek risk altında olan gebelerin sezaryen doğum endikasyonlarını belirleyen çalışmalar yetersizdir. O nedenle bu çalışma çok ileri maternal yaşa sahip gebelerin doğum şekli ve sezaryen endikasyonlarını belirlemek amacıyla yapıldı.

\section{Yöntem}

Bozok Üniversitesi Uygulama ve Araştırma Hastanesinde doğumunu yapan, 40 yaş ve üzerindeki gebelerin dosyaları geriye dönük olarak incelendi. Incelemeye geçtiğimiz iki yılın verileri dâhil edildi. Geçtiğimiz iki yılda Bozok Üniversitesi Uygulama ve Araştırma Hastanesinde 130 40 yaş ve üzeri maternal yaşa sahip olan gebenin doğum yaptığı belirlendi ve bu süre zarfında doğum yapan 130 gebenin tamamının verileri incelendi. Veriler bilgisayar kayıt sistemi ve hasta dosyalarından toplandı. Veriler araştırmacılar tarafından oluşturulan veri toplama formları ile toplandı. Veri toplama formlarına incelenen dosya ve bilgisayar kayıtlarına göre gebelerin bazı jinekolojik özellikleri, doğum şekilleri, sezaryen doğum endikasyonları kayıt edildi. Verilerin analizinde sayı ve yüzde değerleri kullanıldı. Verilerin tanımlayıcı özellikleri ortalama \pm standart sapma, olgu sayısı ve yüzdeler şeklinde ifade edildi.

\section{Bulgular}

Gebelerin demografik özellikleri Tablo 1'de verildi. Araştırmada yer alan gebelerin yaş ortalaması $41,63 \pm 2,02$, ortalama gravidası $3,93 \pm 1,8$, ortalama paritesi $3,39 \pm 1,3$ olarak bulundu (Tablo 1).

Tablo 2'de çalışmaya dâhil edilen gebelerin doğum şekilleri verilmiştir. Çalışmadaki gebelerin \%63'ünün sezaryen, \%37'sinin normal doğum yaptığı belirlendi (Tablo 2).

Sezaryen ile doğum yapan gebelerin sezaryen doğum endikasyonları Tablo 3'de verilmiştir. Gebelerin \%35'inin sezaryen endikasyonu eski sezaryen doğum, \%21'inin fetal distres, \%13'ünün malprezentasyon, \%11'inin ilerlemeyen eylem olduğu bulundu (Tablo 3).

\section{Tablo 1. Gebelerin demografik özellikleri}

\begin{tabular}{lc} 
Demografik özellikler & Ortalama \\
\hline Yaş & $41,63 \pm 2,02$ \\
Gravida & $3,92 \pm 1,8$ \\
Parite & $3,39 \pm 1,3$ \\
Doğum ağılığı & $3323 \pm 525$
\end{tabular}

Tablo 2. Gebelerin doğum şekilleri

\begin{tabular}{lcc} 
Doğum şekli & $\boldsymbol{n}$ & \% \\
\hline Normal doğum & 48 & 37 \\
Sezaryen doğum & 82 & 63 \\
Toplam & $\mathbf{1 3 0}$ & $\mathbf{1 0 0}$ \\
\hline *Sezaryen ile bir gebe ölü doğum yapmıştır. &
\end{tabular}

Tablo 3. Sezaryen doğum endikasyonları

\begin{tabular}{lcc} 
Endikasyonlar & $\boldsymbol{n}$ & \% \\
\hline Eski sezaryen & 29 & 35 \\
Fetal distres & 17 & 21 \\
Malprezentasyon & 10 & 13 \\
İlerlemeyen eylem & 9 & 11 \\
Preeklampsi & 6 & 7 \\
Sefalo-pelvik uygunsuzluk & 4 & 5 \\
İkiz gebelik & 2 & 2 \\
Diğer* & 5 & 6 \\
Toplam & $\mathbf{8 2}$ & $\mathbf{1 0 0}$ \\
\hline
\end{tabular}

*Endikasyonlar: bir gebede geçirilmiş miyomektomi, bir gebede eklampsi, bir gebede iri bebek, bir gebede kordon sarkması, bir gebede plasenta dekolmanı oluşturmuştur. 


\section{Tartışma}

Günümüzde kadınların çoğu, gebelik planlarını ileri yaşlara erteleme eğilimindedir. Bu duruma genelde kadının sosyal rolünün değişmesi, güvenilir doğum kontrol yöntemleri, bazı nedenlerden dolayı aile yaşamına geç başlama, ileri yaşlarda çocuklarını daha iyi koşullarda yetiştirebilecekleri düşüncesi neden olmaktadır $(12,13)$. Çok ileri maternal yaşta görülme riski artan plasental anomalileri, preeklampsi, eklampsi, hipertansiyon, diabetes mellitus gibi kronik hastalıklar yeni sezaryen endikasyonu oluşturmakla birlikte sezaryen oranlarını da arttırabilmekte$\operatorname{dir}(14,15)$. Bu nedenle tek başına ileri maternal yaş bile sezaryen endikasyonu olabilmektedir (16). Çalışmamızda gebelerin yaş ortalaması $41,63 \pm 2,02$ olarak belirlendi. Yapılan bir çalışmada 40 yaş üstü gebelerin yaş ortalamasının 41,36 $\pm 1,85$ olduğu belirtilmiştir (11). Başka bir çalışmada da yaş ortalaması $40,7 \pm 2,42$ olarak ifade edilmiştir14. Sonuçlar literatür ile benzerlik göstermektedir. Çok ileri maternal yaşa sahip gebelerin genellikle 40 yaş etrafında olduğu görülmektedir.

Araştırmaya dâhil edilen gebelerin gravidası $3,93 \pm 1,8$,

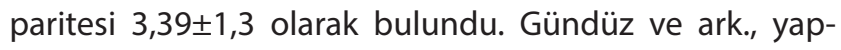
mış oldukları çalışmalarında çok ileri maternal yaşa sahip gebelerin paritesinin 3,54 $\pm 1,72$ olduğunu ifade etmiştir. Yapılan başka bir çalışma da gravide $3,95 \pm 1,58$, parite $2,67 \pm 1,37$ olarak belirlenmiştir. Yapılan çalışmalar yaş artıkça gravide ve paritenin arttığını göstermektedir $(11,17)$.

Çalışmada gebelerin canlı doğan bebeklerin ağırlıklarının ortalaması $3323 \pm 525$ bulundu. Aynığlu ise yaptığı çalışmasında 35 yaş üstü gebelerin bebek ağırlıkları ortalamasını 3120 olarak belirtmiştir (18). Yine ileri yaş gebeler ile yapılan bir çalışma da bebek ağırlıkları ortalaması 3217,0 6651,5 olduğu ifade edilmiştir (19). Yapılan çalışmalar anne yaşı ile doğum ağırlığı arasında bir ilişki olmadığını belirtmektedir. Çalışmanın sonuçları yapılan çalışmalar ile benzerlik göstermektedir.

Çok ileri maternal yaş gebelerin sezaryen doğum oranı $\% 63$ olarak bulundu. Çetinoğlu ve ark. yaptıkları çalışmalarında sezaryen doğum oranının $\% 67,3$ olduğunu belirtmektedir (19). Yapılan çalışmalarda da ileri maternal yaş gebeliklerde sezaryen doğum oranlarının yükseldiği belirtilmektedir $(16,20,21)$. Bu artışa eski sezaryen oranlarının artmasının, ileri maternal yaşa bağlı olarak kronik hastalıkların ve artan gebelik komplikasyonlarının neden olduğu düşünülebilir.

Çalışma da en sık sezaryen nedeni \%35 olarak eski sezaryendir ve primer sezaryen endikasyonu fetal distres \%21 oranında iken en sık koyulan diğer bir endikasyon ise \%13 oranında malprezentasyondur. 40 yaş ve üzeri maternal yaşa sahip gebeler ile yapılan bir çalışmada da en sık sezaryen nedeninin \%55,3 olarak tekrarlayan sezaryenin oluşturduğu, en sık primer sezaryen endikasyonunu ise $\% 12,1$ oranında fetal distres olduğu belirtilmektedir (11). Yapılan çalışmalara ileri yaş gebeliklerde en sık sezaryen endikasyonunun eski sezaryen olduğu belirlenmiştir. Ikincil en sık sezaryen endikasyonu ise fetal distres olduğu belirtilmektedir. Yapılan bir çalışma olarak ise ileri anne yaşına sahip gebelerde fetal distres endikasyonunun ileri maternal yaşa sahip olmayan gebelere oranla daha düşük olduğu ifade edilmektedir $(11,18)$. Çok ileri maternal yaşa bağlı olarak uterin fonksiyonun azalması, pelvik kompliansın yetersiz olmasından kaynaklanabileceği düşünülebilir.

Çalışmamamızda literatürde sık koyulmayan sezaryen endikasyonlarından olan preeklampsi, eklampsi, geçirilmiş miyomektomi, plasenta dekolmanı gibi sezaryen endikasyonları da vardır. Bunun nedeni olarak çok ileri maternal yaşa bağlı olarak hipertansiyon ve plesental yetmezliklere bağlı olduğu düşünülebilir.

\section{Sonuç ve Öneriler}

Sonuç olarak ileri maternal yaş sezaryen oranlarını artırmaktadır ve sezaryen endikasyonları yelpazesi genişleyebilmektedir. Sezaryen oranlarının düşürülmesinde çok ileri maternal yaşa sahip gebelerin düzenli olarak antenatal takibi yapılmalı ve obstetrik ve perinatal riskler konusunda daha dikkatli olunmalı, erken dönemde saptanıp, mümkünse tedavi edilmelidir.

\section{Çıkar Çatışması}

Yazarlar çıkar çatışması beyan etmemişlerdir.

Finansal Destek

Yazarlar finansal destek beyan etmemişlerdir. 


\section{Kaynaklar}

1. FIGO. International Federation of Obstetric and Gynecology; 1958. https://www.figo.org/

2. Krieg SA, Henne MB, Westphal LM. Obstetric outcomes in donor oocyte pregnancies compared with advanced maternal age in in vitro fertilization pregnancies. Fertil Steril 2008;90:65-70. [CrossRef]

3. Cooke A, Mills TA, Lavender T. Informed and uninformed decision making'--women's reasoning, experiences and perceptions with regard to advanced maternal age and delayed childbearing: a metasynthesis. Int J Nurs Stud 2010;47:1317-29. [CrossRef]

4. Türkiye İstatistik Kurumu. Doğum İstatistikleri 2015. Sayı: 21514; 2016. pp.26-141.

5. Yogev Y, Melamed N, Bardin R, Tenenbaum-Gavish K, Ben-Shitrit G, Ben-Haroush A. Pregnancy outcome at extremely advanced maternal age. Am J Obstet Gynecol 2010;203:558.e1-7. [CrossRef]

6. Yeşilçiçek Çalık K, Erkaya R, Karabultlu Ö. Üçüncü basamak bir hastanede 4 yıllık sezaryen doğumlarının oranları ve endikasyonları. Sağlık Bilimleri ve Meslekleri Derg 2018;5:201-9. [CrossRef]

7. Jahromi BN, Husseini Z. Pregnancy outcome at maternal age 40 and older. Taiwan J Obstet Gynecol 2008;47:318-21. [CrossRef]

8. Verma S. Advanced maternal age and obstetric performance. Apollo Med 2009;6:258-63. [CrossRef]

9. Ziadeh S, Yahaya A. Pregnancy outcome at age 40 and older. Arch Gynecol Obstet 2001;265:30-3. [CrossRef]

10. Hsieh TT, Liou JD, Hsu JJ, Lo LM, Chen SF, Hung TH. Advanced maternal age and adverse perinatal outcomes in an Asian population. Eur J Obstet Gynecol Reprod Biol 2010;148:21-6. [CrossRef]

11. Gündüz $S$, Aslan Çetin $B$, Yalçın Bahat $P$, Köroğlu N. Çok ileri anne yaşının perinatal ve neonatal sonuçlara etkisi. Turkiye Klinikleri J Gynecol Obst 2016;26:220-5. [CrossRef]
12. Erez S. Obstetrik ve Jinekoloji (Danforth's Obstetrics and Gynecology -1990 baskısının çevirisi). İstanbul: Alemdar Ofset; 1992.

13. Timor-Tritsch IE. The Multifetal Pregnancy: Sonographic Aspects. Obstetrik ve Jinekoloji Sürekli Eğitim Derg 1999;1:148-53.

14. Abu-Heija AT, Jallad MF, Abukteish F. Maternal and perinatal outcome of pregnancies after the age of 45 . J Obstet Gynaecol Res 2000;26:27-30. [CrossRef]

15. Chen $\mathrm{CL}$, Cheng Y, Wang PH, Juang CM, Chiu LM, Yang MJ, et al. Review of pre-eclampsia in Taiwan: a multiinstitutional study. Zhonghua Yi Xue Za Zhi (Taipei) 2000;63:869-75.

16. Bell JS, Campbell MD, Graham WJ, Penney GC, Ryan M, Hall MH. Do obstetric complications explain high caesarean section rates among women over 30? A retrospective analysis. BMJ 2001;322:894-5. [CrossRef]

17. Kulhan M, Kulhan NG, Naykı Ü, Naykı C, Uluğ P, Ata N. Erzincandaki ileri anne yaşı gebeliklerinin retrospektif analizi. Van Tıp Derg 2017;24:272-8. [CrossRef]

18. Aynığlu, Ö. 35 Yaş üzeri doğum yapan gebelerin demografik özelliklerinin değerlendirilmesi. Kocatepe Med J 2014;15:152-5. http://static.dergipark.org.tr/article-download/ imported/5000117625/5000109112.pdf?

19. Çetinoğlu EÇ, Canbaz S, Ağlan Z, Peşken Y. Samsun il merkezi 2004 yılı ileri yaş gebelik prevalansının saptanması ve sonuçlarının değerlendirilmesi. J İnönü Univ Med Fac 2006;13:167-70.

20. Mills TA, Lavender T. Advanced maternal age. Obstet Gynaecol Reprod Med 2011;21:107-11. [CrossRef]

21. Yılmaz E, Tosun ÖG, Tarhan N, Ayaz R, Turgut E, Karateke A. Perinatal outcomes in advanced age pregnancies. J Clin Exp Invest 2016:7:157-62. [CrossRef] 